\title{
A política de segurança pública no Brasil: uma análise dos gastos estaduais (1999-2010)
}

\author{
Iris Gomes dos Santos \\ José Geraldo Leandro Gontijo \\ Doutorandos do Programa de Pós-Graduação em Ciência Política \\ Faculdade de Filosofia e Ciências Humanas \\ Universidade Federal de Minas Gerais \\ Ernesto F. L. Amaral \\ Pesquisador Associado na RAND Corporation (Estados Unidos)
}

\begin{abstract}
Resumo: Este artigo analisa os gastos estaduais em segurança pública no período de 1999 a 2010, observando principalmente suas relações com as perspectivas ideológicas dos partidos eleitos para o Poder Executivo (governador). Testou-se, sobretudo, a hipótese de que o gasto com a política de segurança pública seria maior em estados governados por partidos de direita, uma vez que parte da literatura nacional aponta para a existência de maior preocupação desse espectro político-ideológico com a função de controle social. Foram utilizados modelos de regressão multivariada que indicaram os seguintes achados: a) variação positiva dos gastos quando os partidos são de esquerda e centro, comparados aos partidos de direita; e b) relativa aproximação dos percentuais de arrecadação investidos em segurança nos estados, independentemente dos partidos nos governos.
\end{abstract}

Palavras-chave: segurança pública; instituições subnacionais; gastos estaduais

\begin{abstract}
This article analyzes the public spending on public safety policy in Brazil in the period of 1999-2010, noting particularly its relations with the ideological perspectives of the parties elected to the Executive (state governments). It was tested especially the hypothesis that spending on public safety policy would be greater in states ruled by right-wing parties, as part of the national literature points to the existence of most concern this political-ideological spectrum with the function social control. We used multivariate regression models and the main findings were: a) increased spending in left-wing and center-wing parties, compared to the right-wing parties; and b) approximation of the percentages of the collection invested in safety policy in the states, regardless of the incumbent parties.
\end{abstract}

Keywords: public safety policy; sub national institutions; public spending 


\section{Introdução ${ }^{1}$}

A temática da segurança pública tem despertado demasiada atenção no cenário político brasileiro nos últimos dez anos, configurando-se como um campo mais amplo e não exclusivo das agendas corporativas de organizações policiais estaduais. Tal atenção, dentre outros fatores, decorre do avanço acelerado da criminalidade e da violência após a década de 1980, notadamente nas regiões metropolitanas e cidades de médio porte - evidenciado pelos índices de violência letal em escala epidêmica ${ }^{2}$ e também pela constatação de que o sistema de segurança pública brasileiro carece de amplas reformas administrativas e institucionais a fim de garantir espaços seguros de convivência democrática e promoção da cultura de paz (SOARES, 2005; SENTO-SÉ, 2005; CANO, 2006). Nessa direção, a segurança pública tem se constituído como um problema recorrente no campo político, tendo em vista que as violências e criminalidades são construções resultantes do confronto de interesses na vida social, representam custos diretos e indiretos que ultrapassam os limites da esfera privada e individual, e, consequentemente, influenciam os investimentos econômicos, gastos com saúde pública, educação, assistência social, geração de renda, arrecadação de impostos e os processos eleitorais em si mesmos (BLAU; BLAU, 1982; BRASIL, 2003; SOARES, 2005; SAPORI, 2007; TOURINHO, 2008).

Análises sobre o setor da segurança a partir do ponto de vista das relações entre instituições, atores e políticas públicas de segurança não têm sido abordadas de forma suficiente pelos estudiosos brasileiros (SAPORI; ANDRADE, 2007). Como afirmam Sátyro (2006), Borges (2010) e Figueiredo (2010), em que pese a situação das instituições estaduais como objeto de estudo da ciência política brasileira, existem poucos trabalhos voltados ao entendimento dos processos de formulação e implementação de políticas nesse nível. Incluem-se nessa lacuna os estudos sobre os gastos e investimentos públicos e sua relação com a política (politcs) no nível estadual. Salienta-se que estudos mais recentes sobre gastos públicos no setor de segurança estão voltados à identificação dos investimentos federais e municipais - o que é relevante, mas não auxilia de maneira objetiva a compreensão dos aspectos relacionados aos gastos no nível de governo, cuja responsabilidade sobre a política é constitucionalmente compulsória.

A finalidade deste artigo, portanto, é analisar quantitativamente os gastos estaduais em segurança pública no Brasil no período de 1999-2010 - abarcando três mandatos do Executivo observando, principalmente, suas relações com o arcabouço político. Testou-se a hipótese de que o gasto em segurança pública é maior em estados governados por partidos cuja orientação ideológica é de direita, uma vez que parte da literatura da área aponta empenhos partidários diferentes, sendo as políticas de segurança prioridades de governos cujos vieses ideológicos enfatizam a função de controle social. Quatro variáveis independentes - variáveis de controle - foram admitidas em função de indicações da literatura e de suas importâncias no arranjo da ação governamental estadual e, consequentemente, pela plausível interferência que podem exercer sobre os gastos: i) regiões geográficas dos estados; ii) índice de criminalidade letal por 100 mil habitantes; iii) capacidade fiscal (receita estadual); e iv) tipos de secretarias estaduais.

\footnotetext{
${ }^{1}$ Os autores deste artigo agradecem aos pareceristas anônimos pelas sugestões e contribuições reflexivas.

2 São considerados casos epidemiológicos os estados ou países que apresentam curvas ascendentes de criminalidade e violência letal, registrando índices acima de 10 mortes por 100 mil habitantes (Organização Mundial da Saúde, OMS).
} 
Para conduzir esse esforço reflexivo, torna-se necessário partir de uma breve contextualização do arranjo institucional da segurança pública no Brasil - próxima seção do artigo. Os dados e a metodologia utilizados estão expostos na terceira seção, seguidos da apresentação e da análise dos resultados - quarta seção - além das considerações finais.

\section{Política pública de segurança no Brasil: aspectos institucionais e políticos relevantes à compreensão da dinâmica dos gastos no setor}

A segurança pública não deve ser compreendida apenas como função e/ou resultado da ação de instituições públicas que se utilizam de mecanismos de controle social ancorados no uso legal da força. Ou seja, a formulação e a implementação de políticas voltadas para o controle da ordem e a prevenção das violências são significativamente mais complexas, tendo em vista que a ordem interna viabiliza a vida coletiva e, simultaneamente, garante os direitos civis dos indivíduos que compõem a coletividade (PAIXÃO, 1988). Assim, os problemas relacionados ao campo desnudam uma série de "falências" não somente do Estado - expressos pelas deficiências estruturais e funcionais do sistema mas também dos padrões e formas de sociabilidade da coletividade que acabam afetando todos os cidadãos, ainda que suas evidências mais dramáticas estejam nas classes pobres e socialmente vulneráveis. Ao mesmo tempo, tais problemas questionam o ideário de consolidação da democracia, a partir da evidência de fragilidades de acesso à justiça e de garantia dos direitos humanos, apontando para a existência, de fato, de um status de cidadania incompleta (ESPINHEIRA, 2004; SAPORI, 2007; SANTOS, 1979).

Embora a Carta de 1988 introduza a segurança no rol de direitos dos cidadãos, tal política no Brasil não é considerada constitucionalmente como integrada ao sistema de proteção social e não existem leis constitucionais de vinculação orçamentária que garantam um padrão mínimo de gastos ou investimentos no setor ${ }^{3}$, nem mesmo uma diretriz básica de aplicação dos recursos. É possível identificar três ordens de fragilidades, inter-relacionadas, nas instituições constitucionais da área: i) conceitual - no sentido de que não define exatamente o que viria a ser avaliado como uma situação ou condição de segurança (COSTA; LIMA, 2014; SANTOS, 2010); ii) estrutural - ao manter um sistema cujas estruturas das organizações burocráticas não são redefinidas em benefício do novo contexto democrático, sendo conservadas separadas e autônomas entre si; ao mesmo tempo, não indica claramente quais instrumentos garantiriam a submissão dessas organizações aos governos estaduais eleitos, nem como dar-se-ia o controle e participação da sociedade civil, ou mesmo da União (GODINHO, 2011); iii) funcional - não há referências à natureza mais específica de conteúdos das políticas (preventivas, repressivas ou investigativas), indicadores desejáveis ou padrões mínimos de intervenção de cada ator para o desenvolvimento do sistema (SANTOS, 2010).

A respeito da fragilidade conceitual, cabe destacar que as definições de segurança pública são, em alguma medida, influenciadas pelo legado autoritário dos governos nacionais. Trata-se de um legado institucional que aproxima a segurança como um direito e prerrogativa do Estado ao passo que imprime

\footnotetext{
${ }^{3}$ Cabe destacar que algumas Polícias Militares são autarquias em regime especial e têm, portanto, orçamento fixo garantido nas receitas estaduais.
} 
um afastamento desta como direito de cidadania (CARVALHo, 2008). Para Costa e Lima (2014), a forma como a segurança pública é retratada nas Constituições brasileiras indica que este é um conceito "em aberto", não há consenso sobre seu significado. Em nenhuma Carta o conceito é claramente definido, e na Constituição de 1988, embora apresente avanços em relações às anteriores, o termo parece surgir como uma oposição à ideia de segurança nacional, "na tentativa instrumental de fornecer ao Estado condições e requisitos democráticos de acesso à justiça e garantia de direitos" (COSTA; LIMA, 2014, p. 484). Segundo Guzzi e Mathias (2010), a responsabilidade das Forças Armadas pela manutenção da Lei e da Ordem reserva-Ihes prerrogativas para participar ativamente do governo sem serem confundidas com o poder político. A separação entre lei e ordem implica ambiguidades claras - a ordem não se molda pela lei, mas pode estar aquém ou além desta, até mesmo da lei que constitui o próprio Estado. As ambiguidades na interpretação de conceitos como ordem pública, lei e ordem, defesa interna e externa ocasionam grandes dificuldades em diferenciar funções e responsabilidades entre as instituições que compõem o setor da segurança, confundem direito individual e dever estatal, tensionando, por vezes, o pacto Estado-sociedade. Tendo em vista a fragilidade conceitual e o legado autoritário da área na América Latina, a partir do final dos anos 1990, organismos multilaterais buscam disseminar o conceito de segurança cidadã4 "na tentativa de provocar rupturas políticas neste cenário e, na sequência, reformas policiais" (COSTA; LIMA, 2014, p. 484).

Isso permite afirmar que há relativo consenso sobre a ideia de que as políticas de segurança desenvolvidas pelos governos, sobretudo de cunho reativo, não têm dado conta da complexidade do fenômeno das violências, acarretando uma conjuntura de descontrole da condição de proteção social e ordem pública, fato que vem mobilizando, no Brasil, a participação de novos atores, especialmente do governo federal, governos municipais, terceiro setor e consultores acadêmicos para a elaboração de propostas de mudanças nas regras formais da política, notadamente relacionadas à quantidade mínima de investimento e à qualidade desta (CANO; RIBEIRO, 2007; CERQUEIRA et al., 2007) e o controle e a transparência sobre os gastos.

Certos esforços por mudanças e avanços institucionais podem ser observados a partir de: i) propostas de emendas nos textos constitucionais; ii) estabelecimento de fundos e programas públicos específicos; iii) aumento da produção intelectual na área; iv) criação de novas instâncias burocráticas em nível nacional e local, ligadas ao tratamento do problema; v) ampliação de canais de participação social em tal domínio; vi) envolvimento formal de outros entes federados na elaboração e implementação de políticas; e, mormente, vii) o alargamento do conceito de segurança pública e da compreensão de seu caráter intersetorial (BRASIL, MINISTÉRIO DA JUSTIÇA/SENASP, 2007). Os esforços por mudanças, em alguns estados, ancoram-se, principalmente, numa tentativa de revisão dos modelos repressivos de exercício de controle social e manutenção da ordem, historicamente vigentes no país (AdORNO, 1998; ZAVERUCHA, 1999; Alvarez; SAlla; SOUZA, 2004).

\footnotetext{
${ }^{4}$ Corresponde à situação política e social de segurança integral e cultura de paz em que as pessoas têm legal e efetivamente garantido o gozo pleno de seus direitos humanos, por meio de mecanismos institucionais eficientes e eficazes, capazes de prever, prevenir, planejar, solucionar pacificamente e controlar as ameaças, as violências e as coerções ilegítimas (PNUD/BID).
} 
Em relação aos aspectos institucionais, são marcos significativos das tentativas de mudanças na política: a) a Secretaria Nacional de Segurança Pública - Senasp (1997); b) o Plano Nacional de Segurança Pública - PNSP (2000); e c) o Fundo Nacional de Segurança Pública - FNSP, durante o governo Fernando Henrique Cardoso. Esses instrumentos estão vinculados ao Ministério da Justiça e apoiam, principalmente, o aperfeiçoamento do sistema de segurança pública a partir de propostas que visam à integração entre políticas de segurança, políticas sociais e ações comunitárias de forma a reprimir e prevenir o crime, reduzir a impunidade e elevar a sensação de segurança dos cidadãos.

Desde tais criações, os governos estaduais vêm sistematicamente recorrendo ao FNSP para incrementar os gastos com a política estadual, fato que intensificou as relações intergovernamentais no setor. O FNSP, por exemplo, tem como objetivo principal realizar, por meio da celebração de convênios e repasses de recursos aos estados, o reequipamento das polícias estaduais, o treinamento e qualificação dessas polícias e das guardas municipais e o aprimoramento tecnológico e científico, além de apoiar projetos na área de prevenção à violência. Souza (2005) aponta que, apesar de haver outras possibilidades de aplicação dos recursos do Fundo, os convênios que mais receberam recursos financeiros foram aqueles que trouxeram a questão do reequipamento em seu bojo. Segundo o autor, isso pode ser explicado de duas formas: i) em função do valor agregado desses itens; ou ii) pela facilidade de as instituições estaduais e municipais demonstrarem carência de equipamentos e estrutura. Nesse sentido, as principais iniciativas da Senasp acabaram relacionadas ao financiamento de ações de reaparelhamento das polícias nos estados (COSTA; GROSSI, 2007) e das guardas civis nos municípios.

Alguns anos depois, no curso do primeiro mandato do governo Lula (2003-2006), ocorreu uma ampliação do papel de intervenção da União na orientação das políticas de segurança pública adotadas pelos governos subnacionais (RATTÓN; BARROS, 2006). Em tal governo, formulou-se outro plano nacional (2003), o qual objetivou criar gradualmente um Sistema Único de Segurança Pública (Susp), com atuações governamentais federais, estaduais e municipais convergentes para a implementação de programas e ações relativos à área de segurança pública e justiça criminal, com ênfase na prevenção à criminalidade e à violência (BRASIL, MINISTÉRIO DA JUSTIÇA/SENASP, 2003). Tal documento também incorporava o conceito de segurança cidadã como um novo marco de compreensão conceitual e orientação das políticas (BRASIL, MINISTÉRIO DA JUSTIÇA/SENASP, 2003; 2007).

Um estudo do Instituto de Pesquisa Econômica Aplicada (Ipea) constatou que no ano de 2007 foram gastos $R \$ 26$ milhões na implantação e modernização de estruturas físicas de unidades de segurança pública; e outros $R \$ 162$ milhões no reaparelhamento das instituições de segurança pública. O balanço aponta também para maior ação do poder público na prevenção à violência (BRASIL/IPEA, 2009) e evidencia que os gastos no setor, pelo menos aqueles provenientes de recursos transferidos pela União, continuam sendo destinados prioritariamente ao aparelhamento dos órgãos, financiando ações de repressão e policiamento ostensivo, indicando que uma parcela dos estados ainda não instituiu reformas burocráticas ou políticas vislumbrando outras possibilidades e alternativas para a aplicação de recursos e investimentos.

Cabe notar ainda que, além da ampliação de investimentos por parte da União nas suas burocracias específicas - Polícia Federal e Rodoviária Federal -, a presença mais significativa do governo 
central no setor da segurança pública pode ter induzido os municípios a um maior dispêndio em gastos com políticas locais relacionadas, como assinalam Lima et al. (2012). Esses autores identificam que os municípios dobraram os seus gastos com segurança no período 2003.2010, num crescimento de $120 \%$, embora a quantidade de municípios que declararam tais despesas tenha crescido apenas $11 \%$ em números absolutos.

Para além dos esforços por mudanças mais recentes no setor e do envolvimento de outros atores, os avanços macroinstitucionais na segurança pública não acompanharam o mesmo ritmo e direção observados na definição dos direitos sociais de cidadania a partir da Constituição de 1988. Autores como Soares (2005), Mariano (2004), Mesquita Neto (2008) e Sapori (2007) afirmam que as instituições relativas à área não sofreram grandes alterações durante o processo Constituinte. Até 1988 e mesmo após esse marco político, praticamente todo o controle dos processos de formulação, implementação e avaliação das políticas públicas de segurança esteve concentrado ora sob o poder dos governos nacionais, em períodos de ditadura, ora sob a alçada das corporações policiais de cada estado federado, em períodos democráticos. A gestão da política manteve-se centralizada e suas ações planejadas e operacionalizadas a partir de burocracias com formações e capacidades distintas (Polícia Civil e Polícia Militar) e, frequentemente, interesses concorrentes e contraditórios.

O resultado dessa herança, para Sapori, significou um caos organizacional e institucional - "a segurança pública, solta e corporativista, com uma revinculação difícil aos Governos Estaduais de estrutura arcaica [...]" (SAPORI, 2007, p. 10). Isso explicaria, em parte, a predominância de um modelo reativo de policiamento e controle da ordem pública, assim como a orientação punitiva e não restaurativa ou de proteção no que diz respeito à atuação junto à parcela da população mais vulnerável aos riscos sociais. Recai, portanto, sobre os estados e suas organizações policiais, sobremaneira, a responsabilidade por adaptar-se ao novo contexto democrático. Ora, sabe-se que práticas e inovações que superem a força da ideia de segurança interna, sob a qual as corporações policiais foram, e ainda são, formadas, implicam um desafio central na direção da formação de uma agenda democrática para o setor e exigem tempo, produção de conhecimento e embate de ideias.

Soares (2005) afirma que o tema da segurança pública acabou sendo negligenciado, entre outros fatores, pela adoção de posturas ideológico-partidárias, à direita, impondo a convicção de que bastaria equipar melhor as polícias, tolerando a brutalidade e a corrupção, para manter o foco nos crimes das periferias circunscritos pelo cordão sanitário que protegia as elites; e, à esquerda, pela defesa de que, sendo as violências e criminalidades causadas por problemas socioeconômicos, não haveria sentido investir em políticas específicas. De acordo com Sapori (2007), uma variante dessa perspectiva "esquerdista" considerava que as únicas políticas públicas capazes de afetar o curso da criminalidade urbana e garantir proteção social seriam aquelas atinentes à provisão dos serviços de educação, saúde, habitação, saneamento e emprego. Havendo, dessa forma, uma sobreposição quase que completa das políticas sociais às políticas de segurança. Outro estudioso da área, Rolim (2006), argumenta que a ausência de uma política específica estava relacionada ao fato de a direita ter assumido uma postura ofensiva em relação à segurança e, em algum momento, ter conseguido monopolizar o discurso na área. 
Acresce-se a isso que o debate está em boa parte impregnado de conotação ideológica, atrelando-se as políticas distributivas ao ideário da "direita" e as políticas redistributivas às posições políticas da "esquerda" (SAPORI, 2007). Em alguma medida, as questões político-ideológicas se confundem com a própria natureza ou conteúdo tradicional dessas políticas (repressivas, reativas, punitivas, discriminatórias). Cano afirma "[...] que em consequência disso não existia sequer a reflexão, nem propostas, dos setores progressistas que se contrapusesse à simples demanda pela ordem por parte dos grupos conservadores" (CANO, 2006, p. 137). Autores como Mariano (2004) e Soares (2005) conferem acentuado destaque à variável "ideologia/clivagem política", no que diz respeito à sua interferência sobre uma estruturação deficiente de reformas e inovações nas macroinstituições do setor da segurança que marcaram o campo no período pós-constituinte, defendendo, inclusive, que esta política sempre foi uma bandeira dos partidos oligárquicos e das elites e um tabu para a esquerda brasileira. Alicerçado sobre tais bases históricas e ideológicas, o sistema de segurança pública brasileiro herda e reproduz uma trajetória de intervenção estatal orientada por estratégias de autopreservação, repressão e controle autoritário da ordem e mediação dos conflitos sociais, não cabendo, portanto, como componente do sistema de proteção social, o que se reverbera sobre a atual crise do setor, evidenciada pelos índices de criminalidade em escala epidêmica e pelo distanciamento entre suas políticas e o conceito de cidadania (Santos, 1979; Draibe, 1993; Fleury, 1994; Carvalho, 2008).

A relação entre ideologia política, partidos políticos e produção de políticas públicas vem sendo discutida pela literatura internacional e nacional. Algumas das conclusões desses estudos apontam para a existência de esforços diferenciados entre as ideologias políticas (esquerda, direita, centro) no sentido de estruturar políticas de proteção e bem-estar social, destacando-se positivamente o papel dos partidos de esquerda (ESPING-ANDERSEN, 1990; CASTLES; MCKINLAY, 1979); o que pode ser verificado, em alguma medida, pelos gastos despendidos na área social ${ }^{5}$. Outros estudos, contudo, argumentam que a política não importa na definição de políticas públicas, uma vez que os resultados políticos estão diretamente associados com a capacidade econômica e o nível de industrialização dos países (WILENSKY, 1976). Há pesquisadores defensores da ideia de que os resultados políticos podem estar relacionados com a ideologia política dos governos, porém não de forma suficientemente definitiva, além de apontarem para a existência de outras variáveis que impactam a composição partidária, como os fatores institucionais (SÁTYRO, 2006; SCHIMDT, 1996; IMBEAU; PÉTRY; LAMARI, 2001).

Entretanto, as discussões sobre partidos e posicionamento ideológico exigem um esforço de reflexão mais ampliado, tendo em vista, por exemplo, que os significados de esquerda e direita se forjam em momentos históricos específicos e a partir de aspectos culturais particulares; havendo, inclusive, localizações mais ou menos de esquerda ou de direita no espectro, além de não se tratar de dimensões necessariamente fixas (LEONI, 2002). Todavia, em virtude da não disponibilidade de espaço neste artigo para o exercício de localização histórica dos grupos políticos em relação ao posicionamento ideológico, optamos pela utilização de uma classificação já existente, formulada originalmente por Figueiredo e

\footnotetext{
${ }^{5}$ Estamos cientes das controvérsias e dos avanços das pesquisas/da literatura em relação à aferição de correlação entre partidos e política pública, os quais passaram a analisar o conteúdo das políticas como variável central em detrimento dos gastos despendidos. No entanto, como primeiro esforço, empreendemos a análise dos gastos pela disponibilidade empírica dos dados, bem como pela necessidade de testar algumas hipóteses já levantadas pela literatura desse setor de política.
} 
Limongi (1999) e ratificada por estudos posteriores como Sátyro (2006), Castro, Nunes e Anastasia (2009), Borges (2010) e Melo (2011).

No caso da segurança pública, embora seja possível refletir sobre a adoção de políticas - mais sociais ou reativas - como variável correlacionada com governos e não com partidos, o que a literatura aponta é a representação determinante dos partidos. Assim, alguns autores internacionais sugerem existir diferenças entre o desempenho dos partidos quando se trata de investimentos na área de defesa social/segurança e política externa (IMBEAU; PÉTRY; LAMARI, 2001), corroborando a afirmação de parte da literatura nacional referendada ${ }^{6}$ e, consequentemente, a hipótese aqui testada. Assim sendo, se crível for a afirmação de que "a segurança pública sempre foi uma bandeira dos partidos oligárquicos e das elites e um tabu para a esquerda brasileira" (MARIANO, 2004), é razoável levantar a hipótese de que o comportamento dos gastos no setor tenderá a ser mais acentuado nos estados governados por partidos de direita, se comparados àqueles de esquerda, especialmente porque a área em questão não costuma ser amplamente avaliada como uma política social, não se tratando, portanto, de uma pauta tão próxima aos partidos de esquerda.

Outro importante aspecto teórico a ponderar é o indicativo na literatura da existência de relativa autonomia das burocracias policiais em relação à dinâmica político-eleitoral, ao mesmo tempo em que se associam a elaboração e implementação da política de segurança, em sentido mais amplo, à pauta dos partidos de direita (Peralva, 2000; ZaVerucha, 1999), dificultando a identificação de autores e contexto: i) Quem, de fato, define diretrizes da política - burocratas autônomos ou políticos de direita, ou mesmo esses dois atores em conjunto?; ii) Em quais contextos institucionais?; iii) Quem decide os gastos e as prioridades de investimento?; iv) Ainda, as políticas (policy) fazem a política (politcs)? E qual o peso das instituições (polity) nessa relação?

Apesar de serem questões relevantes, este artigo é exploratório e, ao analisar se a clivagem/ideologia partidária é uma variável consideravelmente relevante para a compreensão das políticas públicas e do próprio jogo institucional do setor, a intenção é esclarecer, apenas parcialmente, alguns elementos desses questionamentos. Nessa direção, portanto, entendemos que a variável gasto pode ser considerada um indicador importante, embora não exclusivo, do esforço de um governo no que se refere ao desenvolvimento de determinada política (SÁTYRO, 2006), possibilitando indicar se há consistência na afirmação de que a política de segurança é uma pauta dos partidos de direita que, em nível estadual, investiriam e realizariam mais gastos do que os partidos de esquerda. Ou seja, a partir de tais fundamentações teóricas, este artigo testará a hipótese da existência de relação direta e positiva entre partidos de direita e gastos em segurança no âmbito dos estados.

\section{Dados e metodologia}

A base de dados deste artigo é constituída por 293 observações, distribuídas entre os anos 1999 e 2010, com a presença de 10 partidos diferentes, divididos quantitativamente da seguinte forma: PDT - 4 mandatos; PFL/DEM - 12 mandatos; PPS - 4 mandatos; PMDB - 17 mandatos; PP - 1

\footnotetext{
${ }^{6}$ Atenta-se para a particularidade dos estudos internacionais, os quais comparam políticas entre países e não entre unidades subnacionais, como realizamos neste artigo.
} 
SANTOS, I. G.; LEANDRO GONTIJO, J. G.; AMARAL, E. F. L. A política de segurança...

mandato; PPB - 2 mandatos; PSB - 10 mandatos; PSDB - 19 mandatos; PSL - 1 mandato; PT - 11 mandatos. Esse período de 12 anos foi estabelecido em virtude da disponibilidade de dados e da possibilidade de análise de três resultados eleitorais/mandatos distintos (1999-2002; 2003-2006; 2007. 2010), tanto em nível estadual como em nível federal, ampliando a variabilidade de partidos e a alternância de poder entre diferentes clivagens ideológicas nos estados. Trata-se também de um período de mudanças significativas nos padrões de relações intergovernamentais nas políticas do setor e de algumas inovações nas estruturas das burocracias estaduais. O banco agrega informações de gastos totais na função, percentual da arrecadação gasto em segurança, receitas estaduais, região geográfica, população, índice de violência letal por 100 mil habitantes, tipo de secretaria estadual e partido político para todos os estados e o Distrito Federal no período de 12 anos.

Cabem esclarecimentos sobre algumas informações complementares concernentes às variáveis elencadas, a saber: a) 0 índice de violência letal é formado pelo somatório de crimes envolvendo morte (homicídio doloso, latrocínio e lesão corporal seguida de morte) divididos por 100 mil habitantes; b) Reconhecemos que um indicador de capacidade fiscal deve considerar mais do que uma única variável; mas, para os fins pretendidos aqui, tomamos o indicador de receita estadual como uma proxy da capacidade fiscal dos estados; c) Tendo em vista a escassez de estudos empíricos sobre as secretarias executivas estaduais do setor, e diante da impossibilidade de realizar uma pesquisa qualitativa de envergadura nacional, foram pesquisadas todas as nomenclaturas de secretarias existentes no âmbito dos estados brasileiros, ao longo do período recortado para análise, tendo sido identificados cinco tipos de secretaria.

A variável tipo de secretaria foi incorporada com objetivo de captar alguma provável diferença no comportamento dos gastos em função das variações institucionais ou organizacionais. Nessa direção, as secretarias cujas nomenclaturas apresentam o termo "segurança pública", pelo fato de se aproximarem do padrão tradicional de atuação política no campo (reativo, ostensivo), despenderiam maiores recursos que aquelas que apresentaram mudanças/alterações em suas nomenclaturas e estruturas, admitindo termos como "cidadania" e "defesa social". Barreira (2004), ao analisar a trajetória da política de segurança no estado do Ceará, já sinalizava para o peso simbólico da modificação de nomenclatura da secretaria estadual. Segundo ele, a unificação de atividades de diferentes setores que compõem o sistema de segurança pública representa uma responsabilidade política do estado no que diz respeito à coordenação unificada de diferentes burocracias estaduais, além da publicização de um compromisso com a integração das políticas de segurança aos direitos de cidadania. Foram, assim, identificados no período analisado dois conjuntos de secretarias que mantiveram a nomenclatura mais tradicional - Secretaria de Segurança Pública; Secretaria de Justiça e Segurança Pública - e três tipos que apresentaram mudanças - Secretaria de Defesa Social; Secretaria de Segurança, Defesa e Cidadania; Secretaria de Segurança e Defesa Social.

Num primeiro esforço de identificar a existência de correlações lineares entre as principais variáveis elencadas acima, trabalhou-se com duas perspectivas de teste de hipóteses: a) coeficiente de correlação linear de Pearson; e b) teste de qui-quadrado ${ }^{7}$. Importa esclarecer que as relações entre as

\footnotetext{
7 Nos casos de teste da existência e sentido da correlação entre pares de variáveis contínuas, utilizou-se o coeficiente de correlação linear de Pearson $(r)$ e o valor de $p$, ou seja, a probabilidade de rejeição da hipótese nula ( $H O$ ), que nos casos
} 
variáveis gasto total na função segurança pública, percentual de arrecadação gasto em segurança e receita estadual foram testadas a partir de intervalos de valores, daí a utilização de tal teste. Os parâmetros analíticos para a confirmação ou a refutação da existência de relação entre as variáveis no teste de qui-quadrado é o mesmo utilizado no coeficiente de Pearson, valor de $p$.

Para avaliar o efeito da ideologia política dos partidos sobre os gastos em segurança pública nos estados brasileiros, foram estimados modelos de regressão multivariada, os quais permitem ceteris paribus, ou seja, a existência de outros fatores constantes que afetam simultaneamente a variável dependente. Portanto, foram identificadas duas variáveis dependentes para indicar a despesa estadual na execução da política de segurança pública, quais sejam: i) medida de despesa agregada - gasto total na função8; e ii) medida de despesa ponderada - percentual de arrecadação gasto em segurança. Ao utilizar essas duas variáveis dependentes para um mesmo conjunto de variáveis independentes, foi possível captar o impacto destas últimas nos investimentos tanto em termos de volume (gasto total) quanto em termos de proporção (percentual de arrecadação gasto na função segurança pública), considerando o corte de tempo transversal escolhido.

Combinações de variáveis independentes controlam os efeitos da ideologia partidária. A seleção dessas variáveis deve-se à possibilidade de estarem igualmente relacionadas com aspectos que podem incidir sobre o padrão de gastos nas políticas do setor, conforme apontam autores que têm se debruçado sobre o tema (CANO; RIBEIRO, 2007; SAPORI, 2007). A ausência de estratégia política e planejamento para a prevenção da criminalidade, por exemplo, vem sendo apontada pela literatura como uma característica da qual decorre a existência de políticas estaduais reativas, ou seja, que são planejadas e executadas em função da materialização dos problemas - criminalidade, homicídios etc. - e de situações de emergência. Nesse sentido, utilizou-se o índice de violência letal ${ }^{9}$ por 100 mil habitantes como proxy da natureza reativa das políticas dos governos. A ideia é que, ao assumir a predominância de natureza reativa, o efeito da ideologia política sobre os gastos sofre redução. No que diz respeito aos efeitos de arrecadação sobre os gastos, a primeira variável (arrecadação) foi utilizada como proxy de capacidade fiscal $^{10}$ dos estados. A utilização dessa variável e da região geográfica se justifica em virtude das desigualdades constitutivas (estruturais, financeiras, sociais e históricas) entre os estados e regiões do Brasil que interferem sobre as políticas públicas (ARRETCHE, 2003). Por fim, conforme já mencionado, a utilização da variável tipos de secretaria busca também ponderar o fato de que reformas ou inovações na estrutura burocrática podem interferir sobre os gastos. Em alguns estados, por exemplo, os governos optaram por reunir duas pastas administrativas em uma única ${ }^{11}$, o que consequentemente amplia tanto os recursos quanto os gastos.

analisados se trata sempre da não existência de correlação entre os pares de variáveis testadas. Por sua vez, a corroboração da hipótese alternativa (H1) indica sempre a existência de correlação entre as variáveis testadas. Já o teste de qui-quadrado é indicado para captar a relação entre variáveis categóricas.

80 indicador gasto em segurança pública difere do indicador custo da segurança ou insegurança. Para maiores esclarecimentos, ver Cerqueira et al. (2007).

9 Esse índice não é o único a medir o problema da segurança pública, no entanto, foi escolhido por ser, atualmente, o principal indicador utilizado para medir o fenômeno e avaliar as políticas do setor (CANO; RIBEIRO, 2007).

10 Essa variável consta apenas no modelo que utiliza a variável dependente como gasto total, uma vez que a variável ponderada admite colinearidade com os valores de receita, dada sua função proporcional sobre esta.

11 Por exemplo: justiça e direitos humanos com segurança pública. 
SANTOS, I. G.; LEANDRO GONTIJO, J. G.; AMARAL, E. F. L. A política de segurança...

A análise estatística inferencial do Modelo 1 foi realizada com base na seguinte equação: $y=\beta 0$ (gasto total na função segurança pública) $+\beta 1$ (receita estadual) $+\beta 2$ (índice de violência letal por 100 mil habitantes) $+\beta 3$ (regiões geográficas) $+\beta 4$ (formato burocrático) + (ideologia política partidária) $+u$.

Já a análise estatística inferencial do Modelo 2 foi realizada com base na equação: $y=\beta 0$ (percentual de arrecadação gasto na função segurança pública) + $\beta 1$ (índice de violência letal por 100 mil habitantes) + $\beta 2$ (regiões geográficas) + $\beta 3$ (formato burocrático) + (ideologia política partidária) $+u$.

Importa esclarecer que a coleta de informações sobre a segurança pública no Brasil é uma tarefa amplamente reconhecida como "difícil" pelos intelectuais e técnicos da área, tanto no que diz respeito aos gastos e à discriminação de ações implementadas quanto às estatísticas de criminalidade e violência. Por isso, alguns aspectos relacionados à seleção das variáveis dos modelos devem ser esclarecidos. Em relação aos dados de gastos, as principais dificuldades são: a) identificar em quais ações e programas foram investidos os recursos estaduais; b) distinguir a origem do recurso executado, se estadual ou federal, pois há casos nos quais os recursos derivados de transferências voluntárias da União são lançados como provenientes dos cofres do Estado. Por essas razões, optou-se por utilizar o indicador gasto de forma agregada. Ainda assim, estamos cientes de que estudos empíricos (VEIT. WILSON, 2000; CLASEN; SIEGEL, 2007) identificam e problematizam a fragilidade da utilização de gastos como variável dependente - sobretudo gastos agregados - pela dificuldade de identificação e sustentação de análises sobre a qualidade e a eficiência dos gastos e sobre o conteúdo das políticas nas quais os recursos estão sendo aplicados.

Ainda sobre esse aspecto, apesar de a fonte utilizada para a coleta de dados de investimentos e gastos (Tesouro Nacional) atestar que não são computados gastos com pessoal, o que nos leva à ideia de que os gastos são materializados em políticas públicas numa perspectiva mais programática de ação, Lima et al. (2012) chamam atenção para o fato de que as definições oficiais do planejamento da União para a classificação das despesas na função segurança pública e subfunções compreendem grandes categorias de gastos - policiamento, defesa civil e informação e inteligência -, reduzindo a possibilidade de análises mais fidedignas e detalhadas. Os autores apontam para os possíveis equívocos na classificação do tipo de despesa com pessoal inativo na segurança pública e também para o fato de que seu peso nos estados tende a aumentar ao longo das próximas décadas. Embora se constitua como uma observação pertinente - a fragilidade da classificação dos dados e possíveis equívocos no lançamento de despesas com pessoal inativo -, acredita-se que não inviabilize a análise proposta neste artigo, uma vez que apresenta um caráter exploratório e problematizante, e não determinista.

De acordo com Cano e Ribeiro (2007), os problemas mais comuns em relação às estatísticas de criminalidade são: a) a falta de padronização nos registros de ocorrências; b) a duplicidade de registros; c) as limitações de dados e informações sobre os agressores; d) as subnotificações; e e) a incongruência entre os registros das principais fontes - Ministério da Saúde e Secretarias Estaduais de Segurança Pública. Assim, para a coleta de informações sobre violência letal por 100 mil habitantes, optou-se pelos dados disponibilizados pelo Ministério da Saúde, no Sistema de Informações sobre Mortalidade, relativos 
aos anos de 1999 a 2006; e por aqueles disponibilizados pelo Ministério da Justiça, relativos aos anos de 2007 a 2010.

Já a classificação dos partidos a partir de ideologias políticas, embora não seja ponto pacífico ou consensual na literatura, estudos sobre instituições estaduais de Borges (2010) e Sátyro (2006) também se valem da classificação elaborada por Figueiredo e Limongi (1999), adotada neste artigo. Segundo os referidos autores, podem ser considerados como partidos de direita: Partido Democrático Social (PDS); Partido Progressista Renovador (PPR); Partido Parlamentarista Brasileiro (PPB); Partido da Frente Liberal/Democratas (PFL/DEM); Partido Trabalhista Brasileiro (PTB); Partido da Reconstrução Nacional (PRN); Partido Liberal/Partido da República (PL/PR); Partido Trabalhista Reformador (PTR); Partido Progressista (PP); Partido Social Liberal (PSL). Partidos de centro: Partido do Movimento Democrático Brasileiro (PMDB); Partido da Social Democracia Brasileira (PSDB). Partidos de esquerda: Partido dos Trabalhadores (PT); Partido Democrático Trabalhista (PDT); Partido Popular Socialista (PPS) e Partido Socialista Brasileiro (PSB).

A plausibilidade de tal classificação é reforçada ainda pelos estudos de Castro, Nunes e Anastasia (2009) e Melo (2011), que, para operacionalizar uma hipótese que relaciona a localização ideológica dos partidos e a atuação dos deputados estaduais, classificaram os partidos em um continuum esquerda-direita com base em uma média obtida a partir de três questões contidas em um questionário aplicado aos deputados estaduais de todas as assembleias legislativas do Brasil - a classificação, portanto, foi elaborada a partir da própria percepção dos legisladores, como Tarouco e Madeira (2013) sugerem ser possível. Foi solicitado aos deputados: a) que classificassem um conjunto de partidos que não o seu; b) que se autoclassificassem; e c) que classificassem seu próprio partido em uma escala de 1 a 10, na qual 1 representava a posição mais à esquerda e 10, a posição mais à direita. A classificação apresentada pelos autores a partir de tal exercício também é compatível com a utilizada neste artigo. Contudo, considerando as controvérsias existentes na literatura nacional e com a finalidade de refinar nossas análises, trataremos: de forma agregada por ideologia os partidos, num primeiro momento, ao utilizarmos teste de correlação; e de modo desagregado as legendas partidárias, por meio de regressão multivariada.

\section{Análise dos resultados: identificando padrões, relações e impactos}

Os dados relacionados aos gastos (em bilhões de reais) percentuais, brutos/totais, bem como aos percentuais de arrecadação gastos em segurança por regiões, partidos e tipos de secretarias executivas no período de 1999-2010 são apresentados na Tabela 1. Observou-se que o volume bruto de gastos na função segurança pública no período de três mandatos duplicou e/ou triplicou em cada região geográfica, com exceção da região Centro-Oeste - porém de forma diferenciada entre as regiões, o que indica uma relação positiva entre arrecadação por região e gastos brutos no setor.

No que diz respeito aos valores percentuais de arrecadação investidos, ocorre uma evolução de forma mais lenta nas regiões, destacando-se as regiões Norte e Nordeste com ascendência positiva no período. O Centro-Oeste apresentou redução nos valores para cada mandato, ou seja, o investimento em segurança não acompanhou o mesmo ritmo da arrecadação estadual. O Sul aumentou os valores no 
período do segundo mandato em relação ao primeiro, mas apresentou redução no terceiro mandato. A região Sudeste reduziu timidamente o valor dessa medida no segundo mandato, se comparado ao primeiro, mas aumentou-o no terceiro mandato. Dessa forma, os valores de investimento no setor, quando ponderados pela arrecadação estadual entre as regiões (percentual de arrecadação gasto na função segurança pública), variam entre 6,1\% e 10,25\% no primeiro mandato; entre 7,2\% e 10,1\% no segundo mandato; e entre $7 \%$ e $12,1 \%$ no terceiro mandato; evidenciando que, embora o investimento em segurança pública não esteja delimitado por regras macroinstitucionais, os estados mantiveram um padrão nos percentuais de arrecadação despendidos em segurança ao longo da série histórica. Assim, apesar da existência de acentuadas desigualdades entre as arrecadações dos estados e regiões no Brasil, são observadas aproximações quando analisamos o percentual de investimento em função da arrecadação.

Tabela 1

Gastos percentuais, gastos totais e percentuais de arrecadação gastos pelos estados na função segurança pública, organizados por regiões, partidos e burocracias, em bilhões de Reais (mandatos entre 1999-2010)

\begin{tabular}{|c|c|c|c|c|c|c|c|c|c|}
\hline & \multicolumn{3}{|c|}{$\begin{array}{c}\text { Mandato } 1 \\
(1999-2002)\end{array}$} & \multicolumn{3}{|c|}{$\begin{array}{c}\text { Mandato } 2 \\
(2003-2006)\end{array}$} & \multicolumn{3}{|c|}{$\begin{array}{c}\text { Mandato } 3 \\
(2007 \cdot 2010)\end{array}$} \\
\hline & $\begin{array}{c}\text { Gasto } \\
\text { percentual } \\
\text { na função } \\
\text { segurança } \\
\text { pública }\end{array}$ & $\begin{array}{l}\text { Gasto total na } \\
\text { função } \\
\text { segurança } \\
\text { pública }\end{array}$ & $\begin{array}{l}\text { Percentual } \\
\text { de } \\
\text { arrecadação } \\
\text { gasto na } \\
\text { função } \\
\text { segurança } \\
\text { pública }\end{array}$ & $\begin{array}{c}\text { Gasto } \\
\text { percentual na } \\
\text { função } \\
\text { segurança } \\
\text { pública }\end{array}$ & $\begin{array}{l}\text { Gasto total na } \\
\text { função } \\
\text { segurança } \\
\text { pública }\end{array}$ & $\begin{array}{l}\text { Percentual } \\
\text { de } \\
\text { arrecadação } \\
\text { gasto na } \\
\text { função } \\
\text { segurança } \\
\text { pública }\end{array}$ & $\begin{array}{c}\text { Gasto } \\
\text { percentual } \\
\text { na função } \\
\text { segurança } \\
\text { pública }\end{array}$ & $\begin{array}{l}\text { Gasto total na } \\
\text { função } \\
\text { segurança } \\
\text { pública }\end{array}$ & $\begin{array}{c}\text { Percentual } \\
\text { de } \\
\text { arrecadação } \\
\text { gasto na } \\
\text { função } \\
\text { segurança } \\
\text { pública }\end{array}$ \\
\hline \multicolumn{10}{|l|}{ Região } \\
\hline Norte & 5,28 & 2.397 .846 .254 & 6,1 & 7,05 & 6.327 .304 .180 & 8,3 & 8,31 & 11.633 .002 .647 & 8,5 \\
\hline Nordeste & 14,72 & 6.689 .852 .323 & 6,9 & 15,30 & 13.723.727.803 & 7,9 & 19,33 & 27.045.680.673 & 8,5 \\
\hline Sudeste & 57,13 & 25.956.425.191 & 10,25 & 58,17 & 52.183.111.332 & 10,1 & 53,27 & 74.533.207.829 & 12,1 \\
\hline Sul & 13,00 & 5.905 .314 .760 & 7,5 & 12,58 & 11.282 .683 .319 & 8,2 & 11,76 & 16.451 .738 .474 & 7,25 \\
\hline Centro-Oeste & 9,87 & 4.484.276.286 & 8,9 & 6,90 & 6.186.761.903 & 7,2 & 7,33 & 10.249 .583 .928 & 7,0 \\
\hline Total & 100 & 45.433.714.814 &.- & 100 & 89.703.588.537 & - & 100 & 139.913.213.551 &.- \\
\hline \multicolumn{10}{|l|}{ Partido } \\
\hline PDT & 15,83 & 7.190 .348 .586 & 13 & 0,51 & 459.675 .256 & 8,5 & 2,36 & 3.295.305.124 & 8,5 \\
\hline DEM/PFL & 12,11 & 5.499 .898 .883 & 6,4 & 6,77 & 6.070.478.171 & 7,6 & 0,52 & 725.710 .070 & 1,5 \\
\hline
\end{tabular}


OPINIÃO PÚBLICA, Campinas, vol. 21, no 1, abril, 2015, p. 105-131

\begin{tabular}{|c|c|c|c|c|c|c|c|c|c|}
\hline PMDB & 23,88 & 10.850 .868 .034 & 8,7 & 16,46 & 14.763 .735 .308 & 7 & 24,71 & 34.581 .001 .987 & 7,75 \\
\hline PPB & 3,63 & 1.648 .946 .117 & 6 & - & - & - & - & - & - \\
\hline PSB & 1,40 & 635.081 .526 & 6,8 & 20,36 & 18.264 .792 .270 & 9,4 & 7,15 & 10.001 .544 .236 & 7,25 \\
\hline PSDB & 35,50 & 16.132 .006 .033 & 7,4 & 49,22 & 44.151.192.611 & 9,3 & 48,30 & 67.572.200.236 & 9,5 \\
\hline PT & 7,65 & 3.476 .565 .635 & 8,6 & 2,94 & 2.633.594.240 & 8,3 & 10,43 & 14.592.226.546 & 8 \\
\hline PPS & - & - & - & 3,46 & 3.106.039.432 & 7,6 & 3,59 & 5.025 .547 .321 & 10,9 \\
\hline PSL & - & - & - & 0,28 & 254.081 .249 & 6,5 & - & - & - \\
\hline PP & - & - & - & & & & 2,94 & 4.119.678.031 & 8,75 \\
\hline Total & 100 & 45.433.714.814 & - & 100 & 89.703 .588 .537 & - & 100 & 139.913.213.551 & - \\
\hline \multicolumn{10}{|l|}{ Burocracia } \\
\hline $\begin{array}{l}\text { Bur. Seg. } \\
\text { Pública }\end{array}$ & 59,90 & 27.213.590.759 & 7,8 & 41,83 & 37.521 .627 .546 & 7,6 & 42,10 & 58.913 .548 .134 & 7,3 \\
\hline $\begin{array}{c}\text { Bur. Def. } \\
\text { Social }\end{array}$ & 8,01 & 3.639.763.160 & 10,25 & 24,96 & 22.392.176.210 & 10,7 & 26,97 & 37.730.216.451 & 11,5 \\
\hline $\begin{array}{l}\text { Bur. Just. } \\
\text { Seg. Púb. }\end{array}$ & 23,81 & 10.817 .038 .640 & 6,8 & 22,88 & 20.519 .856 .599 & 9 & 20,74 & 29.011.146.391 & 8,9 \\
\hline $\begin{array}{l}\text { Bur. Seg. } \\
\text { Púb. Def. }\end{array}$ & 6,96 & 3.162.145.559 & 6,4 & 8,68 & 7.789.556.628 & 7,4 & 8,44 & 11.805 .922 .141 & 7,65 \\
\hline $\begin{array}{c}\text { Bur. Seg. } \\
\text { Def. } \\
\text { Cidadania }\end{array}$ & 1,32 & 601.203 .696 & 8 & 1,65 & 1.480 .371 .554 & 12,5 & 1,75 & 2.452.380.434 & 13 \\
\hline Total & 100 & 45.433.714.814 & - & 100 & 89.703 .588 .537 & - & 100 & 139.913.213.551 & - \\
\hline $\begin{array}{l}\text { Observações } \\
(\mathrm{N})\end{array}$ & 293 & & & & & & & & \\
\hline
\end{tabular}

Fonte: Elaboração própria com base em dados do Tribunal Superior Eleitoral (1998, 2002, 2006); da Controladoria-Geral da União e das Secretarias Executivas Estaduais.

O comportamento dos gastos brutos/totais e percentuais de arrecadação investidos em segurança apresentou variações também entre os distintos partidos políticos - mais acentuadas nos valores de gastos brutos/totais do que nos percentuais. Há ainda certa oscilação do gasto percentual no interior de um mesmo partido ao longo da série histórica, o que pode estar relacionado com a quantidade de governadores que os partidos conseguiram eleger em cada mandato; e também com as 
respectivas capacidades de gasto (de gestão administrativa) dos estados. PDT, PT e PMDB aumentam a quantidade de governadores, mas mantêm o padrão de percentual de arrecadação gasto em segurança no período. Já o PSDB reduz seu número de governadores eleitos no terceiro mandato, mas aumenta o percentual de arrecadação gasto nesse período. O PPS é o único partido que mantém a mesma quantidade de governos e aumenta o percentual de arrecadação gasto na função - 7,6\% no segundo mandato e 10,9\% no terceiro mandato. O PSB duplica a quantidade de governos eleitos entre o primeiro e o segundo mandato e reduz no terceiro mandato, o que é acompanhado de uma queda no percentual de arrecadação gasto em segurança. Nessa primeira análise descritiva, o PPS e o PSDB se destacam como partidos que, embora não tenham ampliado a quantidade de governos eleitos, expandiram os valores percentuais de arrecadação investidos no período analisado. O caso do PFL/DEM também merece atenção: o partido sofreu grande redução na quantidade de governos estaduais eleitos no período. A legenda já apresentava o segundo menor percentual de investimentos em segurança no primeiro e no segundo mandatos e reduziu a 1,5\% seu percentual de gasto em segurança no terceiro mandato, em função da arrecadação, registrando o menor valor dentre os estados na série histórica.

Salienta-se que os estados com maior arrecadação foram governados por partidos de centro e, consequentemente, investiram maior volume bruto de recursos na área. Esses partidos governaram os estados mais urbanizados do país (São Paulo, Minas Gerais, Rio de Janeiro), e talvez isso justifique uma maior demanda por investimentos no setor. O PSDB, por exemplo, teve três mandatos em São Paulo, dois em Minas Gerais e um mandato no Rio Grande do Sul durante o período, e o PMDB, um mandato em Minas Gerais, Rio de Janeiro e Espírito Santo; e dois mandatos em Santa Catarina e no Paraná. Todavia, embora tenham investido maior volume bruto de recursos, esses partidos não se diferenciaram significativamente dos partidos de esquerda em relação aos percentuais de arrecadação investidos.

Em relação às burocracias estaduais, ainda que a quantidade de secretarias do tipo "Segurança Pública" seja maior, assim como o volume bruto de gastos realizados por estas, os percentuais de arrecadação gastos em segurança nesse tipo de burocracia não apresentaram o mesmo desempenho. 0 maior percentual de arrecadação convertido em gastos em segurança é alcançado pelas secretarias do tipo "Defesa Social" e "Segurança, Defesa e Cidadania". Cabe salientar que essa variável não capta aspectos qualitativos dentro de uma mesma tipologia de secretarias, apenas indica uma provável mudança de comportamentos nos gastos por parte daquelas secretarias estaduais que incorporaram os conceitos de cidadania e defesa social em suas nomenclaturas/estruturas.

A análise descritiva dos dados traz questionamentos sobre a existência de associação direta e positiva entre políticas de segurança pública e partidos de direita no Executivo subnacional no período analisado (1999-2010) - pelo menos no que se refere ao comportamento dos gastos. Os partidos de direita investiram menos, tanto em termos de volume bruto quanto de forma proporcional à arrecadação. Contudo, é preciso salientar, dado que indícios apontam para uma relação direta e positiva entre arrecadação e gastos brutos, o desempenho dos partidos poderia sofrer influência do quantitativo de legendas eleitas.

Os partidos considerados de direita vêm perdendo espaço no quadro político do Executivo estadual no Brasil, e os investimentos em segurança pública não parecem ter sido prioridade em seus governos no período analisado. Todavia, tais achados não descartam a hipótese da existência de 
correlação entre a ideologia partidária e os gastos na função segurança pública. Com o intuito de testar tal hipótese e confirmar as análises dos dados descritivos, procedeu-se à realização de testes de hipótese para medir a intensidade das relações entre as principais variáveis apontadas na Tabela 1 . Conforme explicitado, utilizou-se o coeficiente de correlação de Pearson para a análise de variáveis contínuas, admitindo o valor de $p$ como parâmetro para rejeição ou não da hipótese nula. Assim sendo, obtiveram. se os resultados a seguir. No teste entre as variáveis arrecadação estadual e gasto bruto/total na função segurança pública, os valores de $r=0,8708$ e $p=0,0000$ mostram forte correlação linear com sentido positivo, sendo a probabilidade de não rejeição da hipótese nula muito pequena. A partir de tal resultado, apoia-se a hipótese alternativa da existência de correlação entre a receita estadual e o gasto total na função.

Já no teste da hipótese de existência de correlação positiva entre as variáveis ideologia partidária e gasto bruto/total na função segurança pública, obteve-se um teste de qui-quadrado (com 82 graus de liberdade $)=106.4079$, com valor de $p=0,036$. Ou seja, a probabilidade de não rejeição da hipótese nula é pequena; rejeita-se $\mathrm{HO}$ e apoia-se a hipótese alternativa da existência de relação entre as duas variáveis. A mesma modalidade de teste foi aplicada às variáveis percentual de arrecadação gasto em segurança pública e ideologia partidária, obtendo-se: qui-quadrado (com 10 graus de liberdade) = 26.2254 e valor de $p=0,003$. Nesse caso, a probabilidade de não rejeitar a hipótese nula também é considerada pequena, assim rejeita-se $\mathrm{HO}$ e apoia-se a hipótese alternativa da existência de relação entre as variáveis testadas. Os resultados dos coeficientes de Pearson e dos testes de qui-quadrado, nesses casos, atestam as análises descritivas dos dados, contudo, não possibilitam a realização de inferências causais/explicativas das relações entre estas e/ou outras variáveis que podem influenciar o comportamento da variável dependente.

A identificação de impacto, magnitude e significância estatística das relações causais entre as variáveis no período investigado é possibilitada pela análise dos resultados das regressões multivariadas. Os resultados das regressões estão organizados nas Tabelas 2 e 3 . O primeiro modelo (Tabela 2) adota a variável gasto bruto/total na função como dependente e as seguintes variáveis: receita total; índice de violência letal por 100 mil habitantes; região geográfica ${ }^{12}$; tipo de secretaria estaduali3; e legenda partidária14 ${ }^{14}$ como independentes. O segundo modelo utiliza a variável percentual de arrecadação gasto na função de segurança pública como dependente e, em função disso, exclui a variável receita estadual, mantendo as demais variáveis independentes admitidas no modelo 1.

\footnotetext{
12 A categoria Sudeste foi utilizada como referência nos dois modelos.

13 A categoria Secretaria de Estado de Segurança Pública foi utilizada como referência nos dois modelos.

${ }^{14}$ A legenda partidária PSDB foi utilizada como referência nos dois modelos.
} 
SANTOS, I. G.; LEANDRO GONTIJO, J. G.; AMARAL, E. F. L. A política de segurança...

Tabela 2 (Modelo 1)

Coeficientes e erros-padrão estimados por modelo de mínimos quadrados ordinários (variável dependente: gasto total/bruto na função segurança pública dos estados brasileiros, em bilhões de Reais)

(mandatos entre 1999-2010)

\begin{tabular}{|c|c|c|}
\hline Variáveis & $\begin{array}{l}\text { (Modelo 1) } \\
\text { Gasto total na } \\
\text { função }\end{array}$ & Beta padronizado \\
\hline Constante & $\begin{array}{c}3,683^{* * * *} \\
(192,4)\end{array}$ & \\
\hline Mandato (1999-2002) & ref. 1 & \\
\hline Mandato (2003-2006) & $\begin{array}{c}178,7 \\
(126,4) \\
\end{array}$ & 0,0578651 \\
\hline Mandato (2007-2010) & $\begin{array}{l}385,2^{* *} \\
(153,4)\end{array}$ & 0,1152174 \\
\hline $1^{\circ}$ quartil arrecadação & $\begin{array}{c}-1,236^{* * *} \\
(220,3)\end{array}$ & $-0,3710433$ \\
\hline $2^{\circ}$ quartil arrecadação & $\begin{array}{c}-1,353^{* * *} \\
(191,8)\end{array}$ & $-0,3996587$ \\
\hline $3^{\circ}$ quartil arrecadação & $\begin{array}{c}-1,098^{* * * *} \\
(176,4)\end{array}$ & $-0,3184427$ \\
\hline $4^{\circ}$ quartil arrecadação & ref. 2 & \\
\hline $1^{\circ}$ quartil índice de violência letal & $\begin{array}{c}709,4^{* * *} \\
(163,0)\end{array}$ & 0,2067756 \\
\hline $2^{\circ}$ quartil índice de violência letal & $\begin{array}{c}456,0 * * * \\
(162,2)\end{array}$ & 0,1335261 \\
\hline $3^{\circ}$ quartil índice de violência letal & $\begin{array}{l}338,2^{* *} \\
(166,5)\end{array}$ & 0,0985744 \\
\hline $4^{\circ}$ quartil índice de violência letal & ref. 3 & \\
\hline Região Norte & $\begin{array}{c}-2,043^{* * * *} \\
(237,8)\end{array}$ & $-0,6034639$ \\
\hline Região Nordeste & $\begin{array}{c}-2,064^{* * * *} \\
(198,4)\end{array}$ & $-0,6578568$ \\
\hline Região Sudeste & ref. 4 & \\
\hline Região Sul & $\begin{array}{c}-2,519 * * * \\
(232,8)\end{array}$ & $-0,5145937$ \\
\hline Região Centro-Oeste & $\begin{array}{c}-2,246^{* * * *} \\
(268,8)\end{array}$ & $-0,540858$ \\
\hline
\end{tabular}


OPINIÃO PÚBLICA, Campinas, vol. $21, n^{\circ} 1$, abril, 2015, p. 105-131

\begin{tabular}{|c|c|c|}
\hline PPB & $\begin{array}{c}-759,6^{* * * *} \\
(287,7) \\
\end{array}$ & $-0,0973136$ \\
\hline PDT & $\begin{array}{c}-1,138^{* * *} \\
(277,6) \\
\end{array}$ & $-0,1635691$ \\
\hline PT & $\begin{array}{c}-765,0 * * * \\
(185,0)\end{array}$ & $-0,1732149$ \\
\hline PMDB & $\begin{array}{c}-841,4^{* * *} \\
(168,4)\end{array}$ & $-0,219873$ \\
\hline PSL & $\begin{array}{c}-1,106^{* *} \\
(458,0)\end{array}$ & $-0,0865119$ \\
\hline PPS & $\begin{array}{c}-869,6^{* * *} \\
(283,3)\end{array}$ & $-0,1250135$ \\
\hline PFL/DEM & $\begin{array}{c}-1,041^{* * *} \\
(186,0)\end{array}$ & $-0,2573695$ \\
\hline PSB & $\begin{array}{c}-357,1^{*} \\
(188,7)\end{array}$ & $-0,078997$ \\
\hline PSDB & ref. 5 & \\
\hline Burocracia Segurança Pública & ref. 6 & \\
\hline Burocracia Defesa Social & $\begin{array}{c}-455,7^{* *} \\
(221,0)\end{array}$ & $-0,0857994$ \\
\hline Burocracia Justiça Segurança Pública & $\begin{array}{l}-198,5 \\
(220,5)\end{array}$ & $-0,0422967$ \\
\hline Burocracia Segurança Pública Defesa Social & $\begin{array}{c}-1,191^{* * *} \\
(171,5)\end{array}$ & $-0,3133622$ \\
\hline Burocracia Segurança Defesa Cidadania & $\begin{array}{l}-69,11 \\
(294,5)\end{array}$ & $-0,0088537$ \\
\hline Observações & 293 & 293 \\
\hline $\mathrm{R}^{2}$ Ajustado & 0,698 & 0,698 \\
\hline $\mathrm{R}^{2}$ & 0,723 & 0,723 \\
\hline
\end{tabular}

Fonte: Elaboração própria com base em dados do Tribunal Superior Eleitoral (1998, 2002, 2006); da Controladoria-Geral da União e das Secretarias Executivas Estaduais.

Erros-padrão entre parênteses.

Foi estimado o fator de inflação de variância e não há colinearidade entre as variáveis.

* Significante no nível de confiança de 90\%, ** Significante no nível de confiança de 95\%, *** Significante no nível de confiança de $99 \%$.

1. O primeiro mandato da série foi retirado como referência.

2. $04^{\circ}$ quartil da variável arrecadação foi retirado como referência.

3. $04^{\circ}$ quartil da variável índice de violência letal foi retirado como referência.

4. A região Sudeste foi retirada como referência.

5. O PSDB foi retirado como referência.

6. A Burocracia Segurança Pública foi retirada como referência. 
SANTOS, I. G.; LEANDRO GONTIJO, J. G.; AMARAL, E. F. L. A política de segurança...

Tabela 3 (Modelo 2)

Coeficientes e erros-padrão estimados por modelo de mínimos quadrados ordinários (variável dependente: percentual de arrecadação gasto na função segurança pública nos estados brasileiros, em bilhões de Reais)

(mandatos entre 1999-2010)

\begin{tabular}{|c|c|c|}
\hline Variáveis & $\begin{array}{l}\text { (Modelo 2) } \\
\text { Gasto real na } \\
\text { função }\end{array}$ & Beta padronizado \\
\hline Constante & $\begin{array}{c}9,561 * * * \\
(0,576)\end{array}$ & \\
\hline Mandato (1999-2002) & ref. 1 & \\
\hline Mandato (2003-2006) & $\begin{array}{c}0,211 \\
(0,375)\end{array}$ & 0,0341659 \\
\hline Mandato $(2007 \cdot 2010)$ & $\begin{array}{c}-0,0160 \\
(0,420)\end{array}$ & $-0,0023849$ \\
\hline $1^{\circ}$ quartil índice de violência letal & $\begin{array}{c}0,115 \\
(0,503) \\
\end{array}$ & 0,0167239 \\
\hline $2^{\circ}$ quartil índice de violência letal & $\begin{array}{r}-0,110 \\
(0,506) \\
\end{array}$ & $-0,0161457$ \\
\hline $3^{\circ}$ quartil índice de violência letal & $\begin{array}{l}-0,211 \\
(0,512)\end{array}$ & $-0,0307621$ \\
\hline $4^{\circ}$ quartil índice de violência letal & ref. 2 & \\
\hline Região Norte & $\begin{array}{c}-2,636 * * * \\
(0,573)\end{array}$ & $-0,3891419$ \\
\hline Região Nordeste & $\begin{array}{c}-2,103^{* * *} \\
(0,518)\end{array}$ & $-0,3349416$ \\
\hline Região Sudeste & ref. 3 & \\
\hline Região Sul & $\begin{array}{c}-1,438^{* *} \\
(0,701) \\
\end{array}$ & $-0,1468109$ \\
\hline Região Centro-Oeste & $\begin{array}{c}-2,180 * * * \\
(0,742)\end{array}$ & $-0,2622391$ \\
\hline PPB & $\begin{array}{r}-0,802 \\
(0,898) \\
\end{array}$ & $-0,0513414$ \\
\hline PDT & $\begin{array}{c}1,648^{*} \\
(0,858) \\
\end{array}$ & 0,1184001 \\
\hline PT & $\begin{array}{c}0,862 \\
(0,575)\end{array}$ & 0,097562 \\
\hline
\end{tabular}


OPINIÃO PÚBLICA, Campinas, vol. $21, n^{\circ} 1$, abril, 2015, p. 105-131

\begin{tabular}{|c|c|c|}
\hline PSL & $\begin{array}{r}-0,837 \\
(1,422) \\
\end{array}$ & $-0,0327075$ \\
\hline PPS & $\begin{array}{c}1,080 \\
(0,862)\end{array}$ & 0,0775879 \\
\hline DEM/PFL & $\begin{array}{c}-1,506^{* * * *} \\
(0,577)\end{array}$ & $-0,1860909$ \\
\hline PSB & $\begin{array}{r}-0,683 \\
(0,587) \\
\end{array}$ & $-0,0754971$ \\
\hline PSDB & ref. 4 & \\
\hline Burocracia Segurança Pública & ref. 5 & \\
\hline Burocracia Defesa Social & $\begin{array}{c}3,191 * * * \\
(0,690)\end{array}$ & 0,3002289 \\
\hline Burocracia Justiça Segurança Pública & $\begin{array}{c}0,609 \\
(0,683) \\
\end{array}$ & 0,0648341 \\
\hline Burocracia Segurança Pública Defesa Social & $\begin{array}{r}-0,633 \\
(0,509)\end{array}$ & $-0,0831955$ \\
\hline Burocracia Segurança Defesa Cidadania & $\begin{array}{c}4,353^{* * *} \\
(0,916)\end{array}$ & 0,2786179 \\
\hline Observações & 293 & \\
\hline $\mathrm{R}^{2}$ Ajustado & 0,264 & \\
\hline $\mathrm{R}^{2}$ & 0,317 & \\
\hline
\end{tabular}

Fonte: Elaboração própria com base em dados do Tribunal Superior Eleitoral (1998, 2002, 2006); da Controladoria Geral da União e das Secretarias Executivas Estaduais.

Erros-padrão entre parênteses.

Foi estimado o fator de inflação de variância e não há colinearidade entre as variáveis.

* Significante no nível de confiança de 90\%, ** Significante no nível de confiança de 95\%, *** Significante no nível de confiança de $99 \%$.

1. O primeiro mandato da série foi retirado como referência.

2. $04^{\circ}$ quartil da variável índice de violência letal foi retirado como referência.

3. A região Sudeste foi retirada como referência.

4. O PSDB foi retirado como referência.

5. A Burocracia Segurança Pública foi retirada como referência.

Em relação aos achados da regressão do modelo 1 (Tabela 2), o qual explica 72\% da variância do gasto bruto/total na função de segurança pública, nota-se que, em comparação ao $4^{\circ}$ quartil, os quartis $1^{\circ}, 2^{\circ}$ e $3^{\circ}$ da variável arrecadação estadual possuem impacto negativo, com significância estatística de $99 \%$, sobre a variável dependente (y), isso porque esse último quartil representa o maior intervalo da variável e a capacidade financeira dos estados sofre notável incremento nos anos da série, especialmente no último mandato ( $3^{\circ}$ mandato), como visualizado pelo impacto positivo desse mandato sobre a variável gasto total, com significância de 95\%, se comparado com os mandatos anteriores. Os quartis $1^{\circ}, 2^{\circ}$ e $3^{\circ}$ da variável índice de violência letal por 100 mil habitantes impactaram positivamente a variável dependente, com significância estatística, se comparados ao $4^{\circ}$ quartil (que reúne o maior 
intervalo de índice de violência letal), indicando, contraditoriamente, existir relação entre menores índices de violência letal e maiores investimentos brutos.

Em relação às regiões geográficas, tomando como referência a região Sudeste, todas as regiões apresentaram variação negativa nos gastos, com significância estatística de 99\%; achado consistente à afirmação de uma relação positiva entre receita estadual e gastos brutos/totais, tendo em vista que os estados com maior arrecadação se localizam na região tomada como referência, o que reforça as análises da literatura sobre as desiguais capacidades dos entes subnacionais na implementação de políticas públicas (SOUZA, 2004; ARRETCHE, 2003).

No que se refere à variável independente de principal interesse - partido político - todos os oito partidos apresentaram impacto de variação negativa em comparação com o PSDB (partido de centro tomado como referência), com significância estatística de 99\%; com exceção dos casos do PSB (90\%) e PSL (95\%), indicando que a capacidade de gasto estadual parece ser mais determinante que a ideologia ou legenda partidária na execução da política pública, medida aqui em gastos. Todavia, tal achado exige maior refinamento analítico, pois os valores de "beta padronizado" da variável arrecadação estadual, nos quatro percentis, apresentaram as maiores magnitudes de impacto sobre $y$, ratificando os resultados do coeficiente de correlação de Pearson que indicaram forte correlação entre as duas variáveis em questão (gasto bruto/total e arrecadação).

Sobre o impacto na variável dependente gasto bruto/total causado pelo tipo de secretaria, alude-se que, em comparação à categoria de referência (Secretaria de Estado de Segurança Pública), todos os demais tipos apresentaram impacto negativo, sendo dois desses com significância estatística. A Secretaria de Estado de Defesa Social apresentou uma variação com direção negativa de menos $R \$$ 455,7 milhões, com significância estatística de 95\%, e a Secretaria de Estado de Segurança Pública e Defesa Social demonstrou variação negativa de $R \$ 1,191$ bilhão sobre a variável dependente, mantendo todas as demais variáveis constantes.

O modelo 2, cuja variável dependente é o percentual de arrecadação gasto em segurança, apresentou menor capacidade preditiva (explica $31 \%$ da variância de y). No entanto, o principal objetivo de utilizar uma variável ponderada se deve ao fato de a arrecadação possuir grande interferência sobre os gastos brutos/totais, conforme ilustrado na Tabela 2 e confirmado pelo teste de correlação de Pearson. Desconsiderar tal relação poderia causar distorções e/ou vieses. Ao utilizarmos o gasto ponderado pela arrecadação, e não mais o gasto total, observamos mudanças de valores e inversões de sentido/impacto das variáveis independentes. No modelo 2 (Tabela 3), as variáveis índice de violência letal e mandato perdem significância estatística com a inclusão das demais variáveis independentes, se comparado ao modelo 1 , indicando não existir uma relação direta entre estas e os percentuais de arrecadação gastos em segurança pública.

Embora existam algumas alterações nos coeficientes da variável região geográfica, especialmente aquele pertinente à região Sul, o predomínio é de relação com direção negativa, com significância estatística de $99 \%$ ao se comparar as demais regiões com a região Sudeste. Ou seja, ainda que utilizemos uma variável de gasto ponderada, as diferenças entre os estados e regiões permanecem, mesmo que as distâncias sejam significativamente reduzidas, conforme podemos observar voltando à Tabela 1 - especificamente à coluna percentual de arrecadação gasto na função segurança pública. No 
segundo mandato, por exemplo, os gastos brutos em segurança pública da região Sudeste representaram aproximadamente $58 \%$ de todo o gasto nacional no setor, contra $7 \%$ da região Norte e 6,9\% da região Centro-Oeste, menores participações em tal montante no período. Nesse mesmo mandato, enquanto o Sudeste investiu $10,1 \%$ de sua arrecadação na política de segurança, a região Norte investiu $8,3 \%$.

A variável tipo de secretaria apresenta diferença expressiva nos modelos 1 e 2. Corroborando os dados e análises descritivas derivados da Tabela 1 e contrariando os achados do modelo 1 , nesse segundo modelo a "Secretaria de Estado de Segurança, Defesa e Cidadania" detém maior coeficiente de impacto sobre a dependente, na ordem de 4,3\% de arrecadação convertidos em investimento, comparado ao tipo "segurança pública", deixada como referência; já a "Secretaria de Estado de Defesa Social" mantém sua direção de impacto positivo, correspondente ao percentual de 3,1\% de arrecadação transformados em gastos em segurança, também quando comparada ao tipo "Secretaria de Estado de Segurança Pública", ambas com significância estatística de $99 \%{ }^{15}$. Os demais tipos de burocracia não apresentaram significância estatística.

No caso das legendas partidárias, notou-se um cenário muito diferente do modelo 1 . Ao adotarmos o percentual de arrecadação gasto na função como variável dependente, o comportamento das variáveis partidárias assumiu a seguinte configuração: mantendo-se todas as outras variáveis do modelo constantes, apenas PFL/DEM e PDT apresentaram significância estatística, o primeiro com direção de impacto negativo (significância de 95\%) da ordem de 1,5\%; e o segundo partido com impacto positivo na ordem de 1,6\% de arrecadação convertido em investimentos no setor (significância de 90\%).

De forma sintética, os achados contestam a hipótese que associa o domínio da segurança pública como uma prioridade de governos de direita, ao menos no que diz respeito aos investimentos realizados no setor.

\section{Considerações Finais}

Os modelos de regressão utilizados apontaram para uma fragilidade explicativa do fator político-partidário, tomando como base de análise a ideologia e/ou legendas partidárias, na definição dos gastos no setor de segurança pública no período analisado. Admite-se, contudo, a existência de correlação estatística entre a variável dependente gasto bruto/total na função e a principal variável independente, ideologia partidária. Todavia, como um teste de hipótese não capta detalhadamente a variabilidade entre as categorias testadas, bastaria o fato de os partidos de direita apresentarem redução de sua participação nos governos e, consequentemente, menores gastos brutos/totais e percentuais de arrecadação gastos em segurança para que houvesse algum indicador de correlação entre ideologia e gastos. Desse modo, a análise de regressão multivariada foi utilizada por possibilitar a apuração da variação e do peso de cada legenda partidária no comportamento dos gastos.

15 Salienta-se que alguns estados introduziram o conceito de "defesa social" em suas secretarias a partir de processos de reformas burocráticas que visaram à ampliação do escopo de ações na área e à capilarização de recursos e investimentos e priorização do objetivo de defesa da sociedade. Em certos casos, as funções de justiça e segurança foram reunidas, o que significa maior disponibilidade de recursos. 
No modelo 1 (Tabela 2), todos os partidos apresentaram impacto negativo com significância estatística em comparação ao PSDB. Já no segundo modelo (Tabela 3), dentre o conjunto de oito partidos, apenas um partido de esquerda aparece com impacto positivo e significância estatística (90\%) e um partido de direita surge com impacto de direção negativa e significância de 99\%. Isso demonstra que a legenda ou a ideologia não determinam os gastos nesse domínio de política pública e que, ao modificarmos a variável dependente, tanto os partidos de esquerda quanto os de centro impactam a configuração dos gastos; o que, consequentemente, fragiliza o argumento da existência de relação entre ideologia partidária e política de segurança pública, especialmente no que diz respeito à associação dessa política como uma prioridade ou preocupação maior dos partidos de direita. Para sustentar a ideia de influência da ideologia nos gastos, seria necessário que os partidos de esquerda ou de direita apresentassem padrões diferentes de resultados, em direção negativa ou positiva, com significância estatística. Portanto, é possível afirmar que, ao tomarmos como dependente a variável gasto bruto/ total, os partidos não difiram substancialmente entre si no que diz respeito ao desempenho financeiro nas políticas do setor e que, ao utilizarmos a dependente ponderada pela arrecadação, há alguma diferenciação entre as legendas, porém, não na direção de um padrão de variância que possibilite assumir o peso do partido ou da ideologia como variável explicativa necessária e suficiente.

Em relação à hipótese de predominância de ações reativas dos governos na política de segurança pública, os coeficientes, direção e significância da variável utilizada como proxy, índice de violência letal por 100 mil habitantes, não possibilitaram afirmar que os gastos governamentais são impactados por uma situação de maior incidência de criminalidade letal. Inclusive, ao utilizarmos a dependente gasto bruto/total, o que se percebeu foi uma relação de causa-efeito inversa à hipótese de reatividade dos governos; o que, contudo, não significa afirmar que estes atuam de forma planejada. A verificação dessa relação de forma mais contundente seria possível a partir da utilização de dados desagregados que possibilitassem a identificação do tipo/modelo de política em que os investimentos foram aplicados - políticas reativas, preventivas ou punitivas - e como tais alocações têm impactado os índices de criminalidade.

A utilização da variável receita estadual como proxy de capacidade fiscal conseguiu captar o impacto da capacidade financeira dos estados sobre a política pública, como sugerem autores como Arretche (2003) e Souza (2004). Por sua vez, a análise do percentual de arrecadação investido em segurança demonstrou haver algum padrão entre os estados; sugerindo que, para além do fator de capacidade fiscal, devem existir outros fatores impactando a variável dependente, o que indica a necessidade de estudos mais aprofundados, por exemplo: a) sobre a relação dos gastos e as regras constitucionais dos estados; b) sobre o peso dos interesses das corporações policiais na definição dos gastos na política; c) sobre o elevado custo de manutenção inerente ao caráter ostensivo predominante e/ou à universalidade da política; d) sobre o grau de urbanização e necessidade de investimentos incrementais no setor, em especial o peso dos gastos com pessoal inativo; e e) sobre o legado das políticas prévias. Concordando com Skocpol e Amenta (1986), nesse sentido, o impacto que as políticas prévias podem provocar no poder político de definição da agenda pública, nos padrões de conflito entre grupos de interesse, na influência ou mudança das regras formais, na definição da alocação dos recursos, entre outros aspectos, deve ser considerado. 
Outro ponto relevante é a problematização da relação estabelecida entre Executivo estadual e burocracias, tendo em vista o conflito entre democratização e burocratização. Nesse quesito, estamos cientes de que a construção da variável tipo de secretaria apresenta limitações, tendo em vista que nem sempre o que corresponde às reformas e inovações pode ser representado por nomenclaturas ou tipologias; e também pela impossibilidade de captar a relação entre os atores verificando se os formatos diferentes das secretarias correspondem, por exemplo, a uma agenda diferenciada de governo que impacta os gastos. Conforme exposto, em alguns estados a assunção das políticas preventivas parece ocorrer num contexto de reorganização dos papéis e funções das secretarias estaduais e de ampliação da permeabilidade do Estado a demandas e interesses de outros grupos e comunidades políticas. Entretanto, o esclarecimento acerca da causalidade dessas variáveis exige maior embasamento empírico, inclusive observando os contextos políticos e institucionais da criação de novos formatos de secretarias e suas relações com a ideologia do partido no poder à época de sua criação. Seria, assim, necessário estudar profundamente a estrutura formal e operacional de cada tipo/classificação das secretarias, a fim de aumentar a sua capacidade preditiva, bem como inserir novas variáveis capazes de captar a relação entre burocracia política e burocracia profissional (FIGUEIREDO, 2010) no contexto de formulação e implementação da política.

Avaliando que na conjuntura da ação governamental não é possível desconsiderar as questões relativas ao curso das trajetórias histórico-institucionais e das políticas do setor, cuja tradição ideológica de direita ainda pode ser visualizada em práticas burocráticas e políticas punitivas - e não apenas no padrão de gastos agregados estaduais na função -, cumprirá verificar em uma nova/futura investida sobre os dados, a partir da recente inclusão de um ator na cena política dessa área - o governo federal -, quanto a transferência de recursos da União vem impactando tal realidade, bem como retomar e refinar a hipótese do peso exercido pela politics (incluindo aqui as coalizões) como suficiente para a determinação dos padrões de gasto e formatos das políticas públicas. Cabe notar, além disso, que nosso objeto de investigação aqui se direcionou para a execução da política e sua relação com os partidos. Seria importante realizar pesquisas complementares para identificar o comportamento dos partidos em relação à produção legislativa nesse campo. Como ainda não há estudos que aprofundam a dinâmica partidária nessa esfera, nem mesmo estudos comparados sobre aspectos qualitativos da execução das políticas, não devemos descartar possíveis padrões de influência dos partidos, especialmente os de direita, sobre esse domínio de política pública.

\section{Referências Bibliográficas}

Adorno, S. Consolidação democrática e políticas de segurança no Brasil: rupturas e continuidades. In: ZAVERUCHA, J. Democracia e instituições políticas brasileiras no final do século XX. Recife: Bagaço, 1998.

Alvarez, M. C.; Salla, F.; SouzA, L. A. F. Políticas de segurança pública em São Paulo: uma perspectiva histórica. [online]. Nevusp, 2004. Disponível em: <http//:www.nevusp.org/português>. Acesso em: 10 out. 2011.

ARretChe, M. "Dossiê agenda de pesquisa em políticas públicas". RBCS, São Paulo, vol. 18, n 51, p. 7-9, fev. 2003. 
BarReIRA, C. "Em nome da lei e da ordem: a propósito da política de segurança pública". São Paulo em Perspectiva, São Paulo, vol. 18, n 1, p. 77.86, 2004.

BLAU, J. R.; BLAU, P. M. "The cost of inequality: metropolitan structure and violent crime". American Sociological Review, vol. 47, p. 114-129, fev. 1982.

BoRges, A. "Dinâmica político-eleitoral, burocracia e gasto social estadual". Caderno CRH, Salvador, vol. 23, n 58, p. 91-109, jan-abr. 2010.

Brasil, Ministério da Justiça/Senasp. Plano Nacional de Segurança Pública para o Brasil, 2003.

Sistema Único de Segurança Pública, 2003.2006 (Relatório de Execução), 2007.

BRASIL, INSTITUTO de PESQUISA ECONÔMICA Aplicada (IPEA). Relatórios de avaliação (2006-2009).

CANO, I. "Políticas de segurança pública no Brasil: tentativas de modernização e democratização versus a guerra contra o crime". SUR - Revista Internacional de Direitos Humanos, n 5, ano 3, p. 136-155, 2006.

CANo, I.; RIBEIRo, E. Homicídios no Rio de Janeiro e no Brasil: dados, políticas públicas e perspectivas. In: CRUz, M. V. G.; BATITUCCI, E. C. (orgs.). Homicídios no Brasil. Rio de Janeiro: FGV, 2007.

Carvalho, J. M. Cidadania no Brasil: o longo caminho. Rio de Janeiro: Civilização Brasileira, 2008.

CASTLES, F. G.; MCKINLAY, R. D. "Public welfare provision, Scandinavia and the sheer futility of the sociological approach to politics". British Journal of Political Science, vol. 9, n² 2, p. 157-171, 1979.

CASTRO, M. M. M.; NUnES, F.; ANASTASiA, F. "Determinantes do comportamento particularista de legisladores estaduais brasileiros". Dados - Revista de Ciências Sociais, vol. 52, n 4, p. 961-1001, 2009.

CerqueiRA, D. R. C., et al. "Análise dos custos e consequências da violência no Brasil". Texto para discussão, n 1.284, Instituto de Pesquisa Econômica Aplicada (Ipea), 2007.

Clasen, J.; Siegel, N. A. Comparative welfare state analysis and the "dependent variable problem". In: CLASEN, J.; SIEGEL, N. A. (org.). Investigating welfare state change: the "dependent variable problem" in comparative analysis. Edward Elgar Publishing Limited, 2007.

CostA, A. T.; LimA, R. S. Segurança pública. In: Lima, R. S.; Rattón, J. L.; Azevedo, R. G. (orgs.). Crime, polícia e justiça no Brasil. São Paulo: Contexto, 2014.

CostA, A.; Grossı, B. "Relações intergovernamentais e segurança pública: uma análise do Fundo Nacional de Segurança Pública". Revista Brasileira de Segurança Pública, ano 1, n² 2, p. 6.20, 2007.

DRAIBE, S. M. "O welfare state no Brasil: características e perspectivas". Caderno de Pesquisa, São Paulo, Unicamp, nº 8, p. 50, 1993.

EsPInG-Andersen, G. Three worlds of welfare capitalism. Princeton: Princeton University Press, 1990.

ESPINHEIRA, G. Sociabilidade e violência: criminalidade no cotidiano de vida dos moradores do subúrbio ferroviário de Salvador. Salvador: Ministério Público do Estado da Bahia, Universidade Federal da Bahia, 2004.

FigueIRedo, A.; LIMONGI, F. Executivo e Legislativo na nova ordem constitucional. Rio de Janeiro: Editora FGV, 1999.

Figueiredo, A. C. Executivo e burocracia. In: Lessa, R.; Martins, C. B. Ciência política. Coleção Horizontes das Ciências Sociais no Brasil. São Paulo: Anpocs, 2010.

FLEURY, S. Estado sem cidadãos: seguridade social na América Latina. Rio de Janeiro: Fiocruz, 1994.

GodINHO, L. S. "Depois do $13^{\circ}$ tiro: segurança cidadã, democracia e os impasses do policiamento comunitário no Brasil”. Tese de doutorado em Ciência Política. Universidade Federal de Minas Gerais, Belo Horizonte, 2011.

Guzzı, A. C.; MathiAS, S. K. "Autonomia na lei: as Forças Armadas nas Constituições nacionais". RBCS, São Paulo, vol. $25, n^{\circ} 73$, jun. 2010.

IMBEAU, L. M.; PÉTRY, F.; LAMARI, M. "Left-right party ideology and government policies: a meta-analysis". European Journal of Political Research, $\mathrm{n}^{\circ}$ 40, p. 1·29, 2001. 
LEONI, E. "Ideologia, democracia e comportamento parlamentar: a Câmara dos Deputados (1991-1998)". Dados Revista de Ciências Sociais, vol. 45, nº 3, 2002.

LıMA, R. S., et al. Finanças públicas e o papel dos municípios na segurança pública [online], 2012. Disponível em: <http://www.forumseguranca.org.br/storage/download//fina>. Acesso em: dez. 2012.

MARIANo, B. D. Por um novo modelo de polícia no Brasil: a inclusão dos municípios no sistema de segurança pública. São Paulo: Editora Fundação Perseu Abramo, Coleção Brasil Urgente, 2004.

MeLo, C. R. "Individualismo e partidarismo em doze estados brasileiros". RBCS, São Paulo, vol. 26, n 75, fev. 2011.

Mesquita Neto, P. Segurança, justiça e direitos humanos no Brasil. In: LimA, R. S.; PaUlA, L. (orgs.). Segurança pública e violência: o Estado está cumprindo seu papel?. São Paulo: Contexto, 2008.

PAIXÃo, A. L. Crime, controle social e consolidação da cidadania: as metáforas da cidadania. In: REIS, F. W.; O’DonNEL, G. A democracia no Brasil: dilemas e perspectivas. São Paulo: Vértice, 1988.

Peralva, A. Violência e democracia: o paradoxo brasileiro. São Paulo: Paz e Terra, 2000.

Rattón, J. L.; Barros, M. Polícia, democracia e sociedade. São Paulo: Fapesp, 2006.

RoLıM, M. A síndrome da Rainha Vermelha: policiamento e segurança pública no século XXI. Rio de Janeiro: Jorge Zahar, 2006.

SANTOS, I. G. "Descentralizar, concentrar ou pactuar? Desenhos e estágios de implementação do Sistema Único de Segurança Pública em municípios da Bahia e de Pernambuco". Dissertação de mestrado em Ciências Sociais. Universidade Federal da Bahia, Programa de Pós-Graduação em Ciências Sociais, Salvador, 2010.

Santos, J. V. T. Policia y seguridad ciudadana en Brasil. In: Alvarado, M. B.; SierRa, G. Democracia, gobernanza y desarrollo en el Mercósur: hacia un proyecto propio en el siglo XXI. Uruguay: Unesco/Clacso, 2004.

SANTos, W. G. Cidadania e justiça: a política social na ordem brasileira. Rio de Janeiro: Campus, 1979.

SAPORI, L. F. Segurança pública no Brasil: desafios e perspectivas. Rio de Janeiro: Editora FGV, 2007.

SAPORI, L. F.; AndRADE, S. C. Arranjos institucionais e políticas de segurança pública na sociedade brasileira. In: CRUZ, M. V.; BATITUCCI, E. C. (orgs.). Homicídios no Brasil. Rio de Janeiro: Editora FGV, 2007.

SÁtYRo, N. G. D. Política nos estados brasileiros e gastos sociais: uma análise de série temporal com corte transversal (1987-2002). In: SOUZA, C.; DANTAS NETO, P. F. (orgs.). Governo, políticas públicas e elites políticas nos estados brasileiros. Rio de Janeiro: Revan, 2006.

SCHMIDT, M. G. "When parties matter: a review of the possibilities and limits of partisan influence on public policy". European Journal of Political Research, n 30, p. 155.183, 1996.

Sento-Sé, J. T. Prevenção da violência: o papel das cidades. Rio de Janeiro: Civilização Brasileira, 2005.

Skocpol, T.; AmentA, E. "States and social policies". Annual Review of Sociology, n 12, p. 131-157, 1986.

SoARes, J. L. Apresentação. In: Sento-SÉ, J. T. (org.). Prevenção da violência: o papel das cidades. Rio de Janeiro: Civilização Brasileira, 2005.

SouZA, B. G. "Orçamento e segurança pública: um estudo de caso do Fundo Nacional de Segurança Pública (2000. 2003)". Monografia de Especialização em Políticas Públicas. Universidade de Brasília e Associação Brasileira de Orçamento Público, Brasília, 2005

SouZA, C. "Governos locais e gestão de políticas sociais universais". São Paulo em Perspectiva, vol. 18, n 2, p. 27.41, 2004.

TAROUCO, G. S.; MADEIRA, R. M. "Partidos, programas e o debate sobre esquerda e direita no Brasil". Revista de Sociologia e Política, vol. 21, n 45, mar. 2013.

TourinHo, M. F. P. Violência: um problema de saúde pública. In: LIMA, R. S.; PAULA, L. Segurança pública e violência: o Estado está cumprindo seu papel?. São Paulo: Contexto, p. 101-111, 2008. 
VEIT-WiLson, J. "States of welfare: a conceptual challenge". Social Policy \& Administration, vol. 34, n 1, p. 1.25, March, 2000.

WILENSKY, H. L. The new corporatism: centralization and the welfare state. Beverly Hills: Sage Publications, 1976.

ZAVERUCHA, J. "Military justice in the state of Pernambuco after the Brazilian military regime: an authoritarian legacy". Latin American Research Review, vol. 34, n² 2, p. 43.73, 1999.

Iris Gomes dos Santos - iris.ufmg@gmail.com

José Geraldo Leandro Gontijo - josegleandro@ig.com.br Ernesto F. L. Amaral · eamaral@rand.org
Submetido à publicação em outubro de 2013. Versão final aprovada em dezembro de 2014. 